\title{
A cuarenta años del movimiento estudiantil. Universitarias de los años setenta en la Universidad Autónoma de Puebla, México
}

\section{Gloria A. Tirado Villegas ${ }^{1}$ \\ Elva Rivera Gómez ${ }^{2}$}

Recepción: 4 de setiembre de 2013 / Aprobación: 8 de octubre de 2013

\section{Resumen}

Este trabajo se propone reconstruir el proceso de empoderamiento de las jóvenes universitarias en la década de los setenta, tomando como ejes transversales el género y el significado de un movimiento estudiantil vigoroso en el que adquiere presencia la izquierda. Para desarrollar el texto se consideran como hilos conductores tres elementos: el acceso a la educación superior de las mujeres, la presencia cada vez mayor en órganos de representación, consejeras universitarias y la sexualidad. Se entretejen esas prácticas políticas con las privadas, pues el feminismo en su calidad de movimiento social y desde sus orígenes, ha demostrado que lo personal es político, lo doméstico es social y que lo cotidiano también es trascendente y de esta forma conocer cómo cambiaron las jóvenes universitarias en una década crucial en la historia de esta institución superior.

\section{Palabras clave}

Empoderamiento, feminismo, movimiento estudiantil, sexualidad, masculinidad

\section{Abstract}

This paper aims to reconstruct the process of empowerment of young college women in the decade of the seventies, taking as cross-cutting themes gender and the meaning of a vigorous student movement in which left acquires presence. To develop the text are considered as core three elements: women access to the higher education; the growing presence in representative bodies, University counselors; and sexuality. These policies with private practices, are interwoven as feminism as a social movement and from its origins, has shown that the personal is political, the domestic

$1 \quad$ Mexicana. Doctora en Historia por la Universidad Nacional Autónoma de México, México. Profesora Investigadora del Instituto de Ciencias Sociales y Humanidades Alfonso Velez Pliego de la Benemérita Universidad Autónoma de Puebla (BUAP), México. Correo electrónico: gtirado51@yahoo.com.mx

2 Mexicana. Doctora en Historia y Estudios Regionales por la Universidad Veracruzana, México. Profesora Investigadora del Colegio de Historia de la Facultad de Filosofía y Letras de la BUAP, Máxico. Correo electrónico: elvarivera2000@yahoo.com.mx 
is social and that the everyday is also transcendent, and thus know how college young women changed in a crucial decade in the history of this superior institution.

\section{Key words}

Empowerment, feminism, student movement, sexuality, masculinity

\section{Resumo}

Este trabalho se propõe a reconstruir o processo de empoderamento das jovens universitárias na década de setenta, tomando como eixos transversais o gênero e o significado de um movimento estudantil vigoroso, no qual a esquerda adquire presença. Para desenvolver o texto, três elementos são considerados como fios condutores: o acesso das mulheres à educação superior; a presença cada vez maior em órgãos de representação, conselheiras universitárias; e a sexualidade. Essas práticas políticas se entrelaçam com as privadas, pois o feminismo em sua qualidade de movimento social e desde as suas origens, tem demonstrado que o pessoal é político, o doméstico é social e que o cotidiano também é transcendente, e desta forma, conhecer como mudaram as jovens universitárias em uma década crucial na história desta instituição superior.

\section{Palavras chave}

Empoderamento, feminismo, movimento estudantil, sexualidade, masculinidade

\section{Introducción}

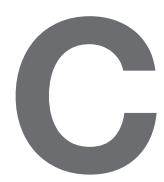

abe preguntarse, ¿cuál es el sentido de revisar lo acontecido hace cuarenta años, además de rescatar la memoria histórica? La historia de las mujeres en el ámbito local tiene muchas lagunas que requieren ser reconocidas, para escudriñar en las fuentes y reconstruir su propia historia. Nuestro afán por reconstruir este proceso es incorporarlos a la historia de la institución, a la historia de los movimientos estudiantiles y a la historia de las y los jóvenes, así como a la historia de las mujeres contemporáneas. Los archivos institucionales son una fuente importante, indudablemente, tanto los documentos como los periódicos están completos para este periodo de estudio; los archivos privados quizá estén por irse donando al Museo Universitario, inaugurado en 2012, y si los hay no están a la consulta y por tanto desconocemos su contenido. Así que, ir tras las huellas de las universitarias parece una tarea pendiente y a nuestro juicio atrayente, la historia oral ayuda a la reconstrucción de ese pasado penetrando en sensibilidades hasta ahora no tocadas. No sobra decir que este año se conmemoran los 40 años de la Reforma Universitaria y por ello nuestro interés en la recuperación de la memoria histórica, será nuestro aporte. 
Antes de proseguir con los planteamientos del tema, permítasenos un paréntesis y hablar en unos párrafos en singular y así desenvolver el hilo conductor de esta historia por escribirse: hace años me propuse entrevistar a universitarias de la época, para desarrollar preguntas que visibilizaran a las mujeres y conocer ¿cómo y por qué habían participado en el movimiento estudiantil de 1968? Los resultados presentados en La otra historia. Voces de mujeres del 68, y en el artículo "De la historia a la nostalgia. Memoria colectiva, el 68 en Puebla, México", fueron una aportación a la historia de las mujeres, y a la de los jóvenes ${ }^{3}$. En aquellos años, de inicios del siglo XXI, solo Lessie Frazier, de la University of South Carolina, y Deborah Cohen de la University of Chicago, abrieron, en este sentido, líneas de investigación con su ponencia "Género, terreno y acción en el 68: la participación femenina y la ciudadanía social en México"4. Entonces solo contados trabajos recuperaban las voces de las mujeres, hoy afortunadamente podemos encontrar más trabajos y parece ser que inicia una nueva ola de lecturas e interpretaciones sobre el 68, desde el enfoque de género 5 .

En efecto, si esto ocurría con los estudios del movimiento estudiantil de 1968, donde la amplia producción bibliográfica en los años recientes muestra un interés creciente para los investigadores, en esta amplia producción bibliográfica son escasos los trabajos que abordan el 68 y recuperan la historia de las mujeres. Todavía seguimos formulando preguntas sobre esas líderes, sobre las presas, quiénes eran, en qué escuelas estudiaban ${ }^{6}$. Las fuentes fotográficas rebelan la presencia de muchas mujeres - de diferentes edades, estratos sociales, actitudes, formas de vestir-, por fortuna hay tesis de licenciatura y posgrado que recuperan su participación a través de las

3 Los primeros trabajos que realizó Gloria A. Tirado se apoyaron en la historia oral, posteriormente continuó realizando una serie de entrevistas y charlas, que le proporcionaron una visión del período comprendido entre 1968 y 1980. Sobre el movimiento estudiantil de 1968 escribió La otra historia. Voces de mujeres del 68, Puebla, Puebla, BUAP/IPM, 2004,184 y De la historia a la nostalgia Memoria colectiva, el 68 en Puebla, México, Revista Diálogos, núm. 1-2, vol. 5, Costa Rica, abril 2004-febrero 2005. Recuperado el 12 de marzo de 2010 de: http://historia.fes.ucrr.ac.cr

4 Frazier, Lessie Jo, Cohen, Deborah, Mexico '68: Defining the Space of the Movement, Heroic Masculinity in the Prison, and Women, The Streets, Hispanic American Historical Review, vol. 83 (4), November, 2003, 617-660. Ponencia presentada en el Seminario Nacional de Movimientos Estudiantiles Mexicanos en el siglo XX, en el año 2001. Este avance se convirtió más tarde en su tesis doctoral. El 68, Nuevos enfoques. Memoria Seminario Nacional de Movimientos Estudiantiles Mexicanos en el siglo XIX.

5 Coincido con Eugenia Allier cuando explica que el 68 ha sido investigado más desde la memoria que de la denuncia y el elogio, pues en un primer momento las publicaciones se centraron en lo ocurrido el 2 de octubre y es hasta los últimos años cuando el movimiento estudiantil parece estar conformándose como uno de los acontecimientos centrales de la historia de México en el siglo XX. Su análisis es interesante y nos muestra por qué el 2 de octubre ha quedado tan presente en la memoria de muchos mexicanos (Allier, 2012, 13).

6 Ana María Sánchez, investigadora del Instituto de Investigaciones Bibliográficas, revisa en su artículo "Los libros del movimiento estudiantil de 1968", la amplia producción bibliográfica sobre el 68 que se encuentra en bibliotecas; identifica una producción de 360 libros, tómese en cuenta que con motivo de la conmemoración de los 40 años del movimiento estudiantil hubo numerosas publicaciones, pese a todo se aprecia la escasez de estudios donde las mujeres son protagonistas (Sánchez, 2008, 121). 
imágenes. Aportaciones como la de Beatriz Argelia González García con su tesis "Las mujeres del 68: de la fotografía a la historia. El caso del periódico La Prensa” (González García, 2011), y el ensayo "Mujeres somos y en el 68 anduvimos. El activismo en la calles" (González García, 2010), visibilizan la activa participación de las mujeres anónimas en este movimiento. Su enfoque novedoso se sustenta en una revisión hemerográfica del material publicado en impresos de corte policiaco de amplia circulación, como el periódico La prensa y los semanarios Alarma y Alerta.

Encontramos también nuevas interpretaciones con apoyo de la historia oral, que sin duda descubren sujetos históricos, que permanecían en el anonimato, por ello las entrevistas, cuestionadas por su subjetividad, contraponiéndolas a "la objetividad de las fuentes documentales", nos brindan elementos relacionados con la construcción cultural, identidad de género, que no siempre podemos encontrar en los documentos. Fuentes como testimonios, historias de vida, correspondencia privada, entrevistas, diarios, contienen una gran riqueza de información para la historia de las mujeres. Trabajos como el de Sabatié Caroline sobre "Le mouvement étudiant au Mexique: l'emancipation féminine en marche", se apoya en testimonios, y el epígrafe deja muy claro su objetivo: "El movimiento del 68 fue una oportunidad para las mujeres [...] para dar un gran paso a la igualdad" (Sabatié, 2006, s.n.).

Si esto decimos respecto a un movimiento estudiantil que pareciera casi agotado en su tratamiento, más aún en las investigaciones referentes al movimiento estudiantil de los años setenta de la Benemérita Universidad Autónoma de Puebla (BUAP), encontramos ausencias, omisiones; algunos autores toman como eje central la historia institucional y los embates de esta con el Estado y la derecha. Escritos por los protagonistas de entonces parecen ver solo en claro oscuro al movimiento estudiantil; un eje temático ha sido el estudio de la derecha y su relación con la violencia desatada en esos años; otro ha sido la historia institucional, los proyectos de los dos rectores, especialmente el del ingeniero Luis Rivera Terrazas?.

Desde esta somera revisión historiográfica la contribución que intenta este trabajo es presentar un resumen de los cambios más significativos de la condición de las mujeres en esa década, reflejo de lo ocurrido en el 68 y de un mayor acceso de mujeres a la educación superior. Precisamos, aunque la BUAP es un escenario regional particular, varias de sus características se presentan en otras instituciones de educación superior del país con escenarios diferentes, como en la Universidad Nacional Autónoma de México (UNAM) y el Instituto Politécnico Nacional (IPN). Uno de estos rasgos es la escasa presencia de las mujeres, reflejada en la matrícula escolar. Tómese en cuenta que en 1968 en

$7 \quad$ Las investigaciones que podemos situar en el primer punto temático fueron publicadas en la primera década del siglo XXI y son: Sotelo, 2002; Dávila, 2001; González Ruiz, 2004. Otros ensayos fueron escritos en los setenta y son de los protagonistas en ese momento. 
la Universidad Autónoma de Puebla (UAP) la matrícula de mujeres era 17\% respecto a la de varones. Incluso en la propia UNAM la matrícula femenina era de 22.8\%, dato que corrobora la tendencia nacional (Díaz Escoto, 2008, 121).

La situación en la Universidad Autónoma Chapingo (UACH) es un ejemplo extremo, pues mantuvo sus puertas cerradas a las mujeres hasta finales de los años sesenta y es hasta principios de los setenta cuando se gradúan las primeras mujeres de la $\mathrm{UACH}$; a partir de los ochenta su matrícula femenina aumenta y se asigna un edificio de los dormitorios a las mujeres ${ }^{9}$. Desde luego reconocemos que si bien hace falta realizar un análisis comparativo del número de estudiantes universitarias en otras instituciones, sabemos que la UNAM, por ser la institución más grande del país, da la pauta y la tendencia nacional.

Conviene entonces plantear la pregunta que desarrolla nuestro discurso ¿Cuáles son esos cambios a partir del empoderamiento que se da con el movimiento estudiantil? Partimos de que no solo las militantes de partidos de izquierda lo lograron, sino que muchas activistas tomaron conciencia de sí y para sí. Fue una coyuntura de gran trascendencia, pues estudios recientes, como el de Elva Rivera Gómez, "De la manifestación al aula. Saberes, silencios e inequidades en la Universidad Autónoma de Puebla (1972-2001)", muestran una relativa pérdida de empoderamiento ante las nuevas formas de administración universitaria, precisamente con la "modernización educativa"10.

Las formas de subordinación de las mujeres adquieren nuevos rostros y aparecen maquilladas en una política pública diseñada por la Asociación Nacional de Universidades e Instituciones de Educación Superior (ANUIES), que evalúa la equidad de género. Hoy nuevamente los concursos de "Reina del Día del Estudiante" son reivindicados por muchas jóvenes, corresponden al escenario que vive la juventud en el país. También llama la atención, el escaso interés por participar en los órganos de gobierno de la BUAP, sobre todo en el Consejo Universitario -máximo órgano de gobierno-, o en los consejos de unidad. La presencia femenina es observada en cargos de suplente, y en la mayoría de los casos, las intervenciones parecen poco críticas y carecen de liderazgo. Amén de reflexionar a la luz de los últimos acontecimientos y el surgimiento del movimiento Yo Soy 132, cuyos reflejos habremos de notar ${ }^{11}$. Dicho lo anterior, pasaremos a mostrar esos cambios significativos.

$8 \quad$ Desde 1988 fue nombrada Benemérita Universidad Autónoma de Puebla, antes de esa fecha se llamaba UAP.

9 Verónica Vázquez afirma que "desde los cincuenta comenzaron a graduarse agrónomas de otras instituciones mexicanas (la Universidad Antonio Narro, el Instituto Tecnológico de Estudios Superiores de Monterrey, la Escuela Superior de Agricultura Hermanos Escobar de Ciudad Juárez)" (Vázquez, 2009, 81-82).

10 En su tesis doctoral Elva Rivera realiza una investigación exhaustiva sobre un periodo de 30 años y muestra los cambios y permanencias en materia de género, inequidades, invisibilidades y, sobre todo, lo ocurrido en los últimos años (Rivera, 2010, inédita).

11 Movimiento estudiantil que se dio a conocer en el año 2012, su fuerza y visibilización se apoyó en las 


\section{Dos pasos adelante y uno atrás}

Es indudable la significación que tuvo el movimiento estudiantil del 68 en la formación política de las jóvenes universitarias, la conciencia social que generó. Este empuje permitió que en universidades altamente masculinizadas, como la UAP, las mujeres lograran un ascenso de manera casi natural, ascenso que se percibe en la participación de los órganos de gobierno, en la docencia y en la matrícula escolar. Como se ha señalado ya, el 68 provocó que se retara al poder masivamente y pudieran acuñarse las expresiones de la disidencia sin temor a ser llamada comunista, revoltosa, mitotera ${ }^{12}$. Posibilitó la igualdad de géneros en universidades, como la UAP, que eran de ambiente masculinizado. A causa del 68 se modernizó el contenido de las materias en las instituciones de educación superior. Con lo dicho anteriormente no deseamos caer en el elogio al 68, por el contrario, deseamos marcar las grandes diferencias entre un momento y otro, y desde luego las formas de elegir a las autoridades, otro cambio sustancial que se dio en 1972, al proponerse el voto universal directo y secreto para elegir al rector, modificaciones a los planes y programas de estudio ${ }^{13}$.

El movimiento de 1968 fue un prisma cultural que modificó la forma de ver la vida, concientizó a las y los jóvenes sobre la pobreza, la injusticia, la intolerancia y la inexistencia de derechos humanos. Desnudó el sistema político autoritario, anquilosado y lleno de barbarie. Desnudó también el anquilosamiento de las instituciones de educación superior. En todo caso, el movimiento estudiantil se volvió la conciencia del pueblo. Pero sobre todo, las mujeres se empoderaron ${ }^{14}$, aunque este empoderamiento no significó equidad de género, sí se materializó en una participación activa en la representación de los órganos de gobierno de la institución, en las organizaciones estudiantiles (llámese comités de lucha, jefes de grupo, asociaciones) y cuando se inició la creación de los sindicatos universitarios, ellas estuvieron presentes y lucharon por sus reivindicaciones. Así en los años setenta se unen quienes habían participado en 1968 con las nuevas generaciones escolares (la del 68 y la de la década de 1970) estas conforman una identidad y una generación. Entendemos por generación -como la define Julio Aróstegui (Aróstegui, 2004, 111-121), aquella donde lo que interesa es el punto de interacción y no el de la edad, que atiende más a lo biológico-, pues esta generación de mujeres durante estos

redes sociales. Nació en la Universidad Iberoamericana, en su sede del Distrito Federal y pronto se involucraron estudiantes de casi todas las instituciones de educación superior a nivel nacional.

12 Mitotera: expresión coloquial que significa alborotadora o que gusta de meterse en líos.

13 Durante 1971 funge una Junta Administrativa, el movimiento de Reforma Universitaria propuso que el rector fuese electo por votación de los estudiantes y profesores, el 18 de septiembre se elige en el Consejo Universitario al químico Sergio Flores Suárez.

14 Varias de las entrevistadas que aparecen en La otra historia del 68, hablan de igualdad de género, en la institución y en los espacios públicos, y hacían lo mismo que los varones al hablar, hacer pintas, elaborar propaganda. 
años acompañó a varios actores sociales del presente, líderes que requieren también una historia propia.

Una característica de este periodo fue el ascenso del marxismo en las instituciones de educación superior, esta difusión proveyó de armas ideológicas a los estudiantes, la Guerra Fría fue el escenario por el que este discurso prendió contra la intervención del imperialismo en América Latina. El marxismo se incorporó a los planes y programas de estudio. El proceso que vivió el movimiento estudiantil después de levantada la huelga de 1968, siguió el curso de diversas inquietudes, una de estas surgió en 1969, cuando se presentó un problema de acceso a la universidad, especialmente en el nivel de preparatoria, pues muchos alumnos fueron rechazados. La primera respuesta de los comités de lucha fue abrir una preparatoria, reconocida después por el Consejo Universitario como Preparatoria Popular Emiliano Zapata. La lucha por lograr su institucionalización fue el centro de atención de los universitarios, demanda que se sumó a la entrega de subsidio federal que casi siempre retrasaban el gobierno federal y el gobierno estatal.

En este marco algunas jóvenes se incorporaban a los comités de lucha, que en cada escuela se habían formado y, ante la polarización del discurso de la iglesia -del gobernador y autoridades, como sectores de la derecha-, contra la universidad, volcó al movimiento estudiantil a salir de los muros universitarios y se fundió con el movimiento popular. La presencia de una izquierda identificada por los medios de comunicación y por los grupos de la derecha, fue delineando estrategias no siempre claramente fraguadas por una dirección, pues muchas veces se presentaban reacciones espontáneas. Las universitarias se vinculan con los movimientos populares, donde participan mujeres urbanas y rurales, obreras, amas de casa y forman otras redes de sociabilidad, afectos y construyen intereses comunes.

Surgen muchas jóvenes valientes y valiosas, como Natalia Sardá Cue, universitaria fuera de serie, se casó muy joven, de apenas catorce años, dato relevante considerando que la mayoría esperaba unos años más. Estudiaba la preparatoria, pero más importante de sopesar es que combinó la maternidad, con su carrera, la docencia, y con las actividades que le atraían, como ella lo describe: "Mi vida era la Universidad y mi hija, andaba conmigo en los patios de la Universidad", ella refiere que su hija es de las tantas, "hijas de los patios de la Universidad", como las hijas de Joel Arriaga o de algunos de sus compañeros que vivían una situación parecida a la de ella. "Los fines de semana tenía que ir a las poblaciones, para estar en las reuniones con los electricistas" (Sardá Cue, 2006) ${ }^{15}$.

El caso es singular y a la vez forma parte de una generación, pues unos años después Natalia se incorporó a dar clases en la Preparatoria Enrique

15 Entrevista realizada a Natalia Montserrat Sardá Cué en los días 9 y 12 de enero del año 2006. 
Cabrera, por la que luchó para que se le reconociera como incorporada a la universidad. Baste decir que fue ella quien propuso el nombre de la preparatoria Enrique Cabrera en enero de 1973, quien muriera asesinado el 20 de diciembre de $1972^{16}$. Natalia había hablado con Cabrera horas antes de su asesinato, tenía un aprecio especial por Enrique. La trayectoria laboral de Natalia mostró una línea ascendente, pues pronto adquirió una plaza de hora clase en la Preparatoria Benito Juárez. En octubre de 1974 quedó vacante una plaza de técnico en dicha preparatoria, para entonces, Natalia cursaba el segundo semestre de psicología, esto coincide con un momento en que las personas no querían trabajar dada la inestabilidad de salarios.

Sin detenernos más en Natalia, quien nos ha permitido ilustrar el comportamiento casi generalizado de muchas universitarias, continuamos con esta generación: evidentemente, algunas se incorporaron a la academia siendo estudiantes aún, otras ya eran pasantes y las menos tituladas, pero el denominador común fue la juventud. No se trataba de un relevo generacional, sino que dos fenómenos se imbricaron: por un lado la renuncia y/o expulsión de catedráticos (que no estaban de acuerdo con la reforma universitaria) y por otro lado, el nacimiento de nuevas preparatorias, la incorporación de un hospital civil a hospital universitario y la creación de algunas unidades. La coyuntura favoreció la inclusión de muchas jóvenes. El ambiente dentro y fuera de la universidad era de violencia verbal y en varias ocasiones se dieron enfrentamientos entre los grupos universitarios, incluso se hizo uso de armas. Las constantes pugnas entre dos grupos: los que estaban a favor de la reforma universitaria (demos) y los que estaban en contra (fúas). La cotidianeidad rebasaba un orden institucional y era introyectada por las jóvenes en diversas dimensiones, y las que se comprometían sabían lo que podría ocurrir, militaran o no en la izquierda, pues el simple hecho de repartir propaganda o subirse a un autobús para informar, las hacía proclives a sufrir o presenciar un ataque, físico o verbal.

\section{La sexualidad}

El tercer elemento a considerar como parte del proceso de empoderamiento es el de la sexualidad. Por un lado, las jóvenes habían modificado sus prácticas sexuales, veían bien el consumo de la pastilla anticonceptiva. Sus prácticas no siempre coincidían con el discurso institucional sobre la sexualidad y en torno a la salud. En la Conferencia Nacional sobre Población y Desarrollo Social, realizada en la ciudad de México en 1974, el subsecretario de Salud se sirve de la consigna feminista "anticonceptivos para no abortar". Una

16 Enrique Cabrera Barroso conocido dirigente estudiantil, preso dos veces en 1961 y 1966. Desde 1970 era docente universitario y en 1972 fue nombrado jefe del departamento de Extensión Universitaria, identificado con los grupos de izquierda. Sus programas de trabajo al frente del departamento. de Extensión comprendían módulos de atención a la salud en lugares marginados. Lo asesinaron al llegar a su casa, el crimen jamás fue esclarecido y mostró la violencia que se vivía en esos años. 
recomendación internacional a causa de la alta tasa de población, contrario al discurso que la propia Iglesia católica propaga por diversos medios.

Así, las mujeres viven las contradicciones en las instituciones: por un lado, se promueve la castidad, se cuestiona el uso de las pastillas anticonceptivas; y por otro lado, se impulsa la anticoncepción, se legitima la doble moral y se penaliza el aborto. Muchas jóvenes viven su sexualidad y retan estas contradicciones. La familia es el discurso de trasfondo en estas circunstancias, mientras las jóvenes defienden su sexualidad y su derecho a decidir. Lemas como el de "Prohibido prohibir" lo relacionan con la liberación sexual. El matrimonio tradicional es cuestionado por algunas que deciden la opción de la unión libre ${ }^{17}$. Si bien la píldora anticonceptiva fue introducida en 1955 no significaba que las jóvenes la incorporaran mecánicamente a su vida sexual, poco a poco fue siendo utilizada.

El derecho a decidir es, como siempre, la clave del progreso de las mujeres, tal como lo es para los hombres. Quince años después de su introducción, 20 millones de mujeres estaban ejercitando ese derecho tomando la pastilla, y otros 10 millones usaban el dispositivo intrauterino o DIU (Holland, 2007, 195).

Hasta mediados de la década de 1970, todavía existían dudas sobre los efectos secundarios que tendría el consumo de la píldora, había profundas razones religiosas. Por ejemplo, en Italia se decía: "La Iglesia católica prohíbe el uso de la píldora anticonceptiva y se calcula que solo entre el 8 y el 10 por ciento de las mujeres italianas las usan". Un notable ginecólogo italiano, el profesor Rubblani, de Roma, ha dicho que "las razones religiosas son ahora secundarias". Opina que más italianas rehúsan tomar la píldora debido a "sus temores de posibles efectos dañinos". Pero en otros países, como en Inglaterra, la píldora se incorporaba poco a poco y había opiniones de médicos que influían como los de la "Asociación Médica Británica", que llegó a la conclusión de que la píldora es un riesgo menor que fumar, nadar o manejar" (El Sol de Puebla, 1970, agosto 19).

¿Qué ocurrió en la vida de las universitarias? Decidieron planear su vida de otra manera. Una investigación de los años ochenta -que estudia a las académicas universitarias, aplicando una encuesta- revela que el promedio de edad para ser madre pasaba los 25 años y el número de hijos en promedio era de dos; como efecto de que los hábitos y prácticas sexuales se habían modificado. Agregaba, entre más estudios menor número de hijos (Quijano, s.a., 105). Tales datos descubren otros comportamientos:

Todas practican la anticoncepción artificial. Usan preferentemente píldoras o inyecciones [...]. Más del $50 \%$ de las académicas entrevistadas tienen entre 25 y 29 años de edad, y la mayoría son mujeres sin pareja [...]. El 63\% de las académicas entrevistadas eligen a sus parejas entre hombres con edades

17 Sobre este tema Gloria Tirado lo desarrolla ampliamente en: Tirado, 2012, 147-169. 
similares a las suyas. El marido con disposición a ser "compañero y amigo" parece ser más común, entonces, que el marido "padre y tutor" (Quijano, s.a.,106).

El uso de la píldora anticonceptiva y cualquier método que un matrimonio o pareja decidiera era combatido por la Iglesia, las organizaciones católicas y por el Comité Nacional Provida, delegación Puebla, que aglutinaba a varias organizaciones que lo combatían activamente. Para este comité el feminismo provocaba desacatos ante Dios, tomamos su opinión publicada en un desplegado de hoja completa:

Es fácil comprobar que avanzamos a pasos agigantados en el cumplimiento de estas etapas: el auge de la pornografía, la aparición de la promiscuidad sexual entre jóvenes, los movimientos feministas y las campañas de control natal, alcanzan ya niveles de escándalo. Si a esto aunamos la aceptación de la práctica del divorcio, la proliferación de madres solteras y la práctica del aborto provocado, podremos inferir, no sin temor, el futuro que podría esperar a México y con él a nuestros hijos (El Sol de Puebla, 1978, 21 de abril).

En otra parte de este desplegado afirman también que:

Es en esta fase cuando prolifera la pornografía, cuando aparecen los planteamientos de la llamada "revolución femenina", así como el ataque y destrucción sistemática del pudor; en síntesis, todo el planteamiento de la llamada sexualidad. Valores como la castidad, modestia, recato y virginidad son ridiculizados (El Sol de Puebla, 1978, 21 de abril).

Noticias en las que descalificaban al "movimiento de liberación femenina" alertaban a la población, como en una nota en la cual informaban que en Nueva York se daban bailes entre mujeres al son de una orquesta femenina y guarderías infantiles atendidas por hombres, serán las características salientes de una conferencia que el movimiento de Liberación Femenina realiza en esta ciudad durante el fin de semana. Los hombres han sido totalmente proscriptos de esta conferencia de dos días en la Universidad de Columbia, habiéndoseles encargado únicamente el trabajo de cuidar a los niños de tres guarderías, indicó hoy un portavoz de la comisión organizadora (El Sol de Puebla, 1971, 22 de marzo).

La virulencia de los ataques contra el feminismo era constante, y es que el feminismo era el otro fantasma que recorría al mundo, cuando algunas se declaraban feministas y otras no, lo asumían de manera personal, y no siempre encontraban eco en los grupos de izquierda que calificaban a este movimiento de pequeño burgués. Lo cual volvía más compleja la identificación con el feminismo, o bien algunas trataban de evitar que las tacharan desde una visión simplista si estaban o no en un bando, incluso que cuestionaran sus preferencias sexuales para descalificarlas. Por ello interesa conocer ¿cómo llegaron esas ideas al país?, ¿cómo influyó el feminismo internacional?, ¿qué relación tuvo con el movimiento estudiantil de 1968 y con el de los setenta en 36 Puebla? Son muchas las interrogantes que surgen alrededor de este proceso, 
que no necesariamente se pretende responder en este pequeño apartado. Baste decir que el ambiente generalizado era altamente masculinizado, mejor dicho machista.

Tampoco podemos afirmar que ese empoderamiento era al unísono, ni todas estaban dispuestas a utilizarlo. La asimetría que se vivía en la institución tampoco era visible a los ojos de las jóvenes universitarias, porque muchas de ellas colaboraban con gran entusiasmo en este proceso, estaban comprometidas con el mismo, más aún algunas agradecidas con su incorporación a la docencia, como lo expresan en algunas entrevistas. En este universo en el cual se movían les hizo ver arrebatos, injusticias, malos tratos de sus compañeros, como algo secundario, algunas incluso naturalizaban estas asimetrías, hasta de marginación o subordinación, que después pudieron cuestionar con propuestas y aglutinarse en torno a una identificación política, y en torno a la diferencia sexual, "un movimiento que quedó como el debate entre la defensoras de la igualdad y las que sostienen la diferencia" (Ergas, 1994, 163). Agregaría que en Puebla quedó un debate, implícito, entre marxistas, comunistas y las jóvenes que desafiaban las nociones de igualdad y proclamaban la diferencia.

\section{La visibilidad de las mujeres en las fuentes impresas}

A diferencia que en años anteriores, incluido el 1968, las mujeres no son mencionadas en las notas periodísticas. En la década de 1970 los periodistas se dirigen a ellas, e insisten en llamarlas el motor del desarrollo, son ellas las que pueden transformar la economía. Parecía que eran vistas como el sujeto revelador, pues en los periódicos locales, como Novedades y El Sol de Puebla se abre una sección dedicada a ellas, la sección de Novedades bajo el título "Mujeres, mujeres, mujeres". En esta sección se incluyen entrevistas a estudiantes de diferentes escuelas, generalmente recién ingresadas, y les preguntan por qué escogieron esa carrera, las preguntas reiteradas, entre otras, son: ¿qué harán cuando se casen, si ejercerán o no la carrera?, ¿cuáles son los retos de las mujeres?, ¿cómo las tratan sus compañeros en la carrera que escogieron?

Pese a lo que pudiera pensarse de la manipulación en las preguntas, las entrevistas resultan útiles para comprender sus inquietudes, su interés por la carrera, su visualización, conocer la percepción entre las que provienen de otros estados de la República y comentan las diferencias de trato con las y los poblanos, opinan que el ambiente es conservador. Una que otra señala los avances del feminismo. En El Sol de Puebla no existe una sección específica, pero son frecuentes los temas sobre mujeres a cargo de distintas reporteras que buscan mujeres profesionistas y las entrevistan con un mayor énfasis a las que estudian carreras masculinizadas como Ingeniería Civil, a la cual ingresó a estudiar la primera mujer en 1971. 
No sobra traer al texto la respuesta de la entrevistada María Estela Guerrero García, quien es alumna de segundo año de la carrera de Ingeniería Civil, considerada entonces "la isla de los hombres solos". María Estela es inteligente y con muchos deseos de que la mujer destaque en ese campo, y afirmó en dicha entrevista que:

Yo estudiaba Arquitectura pero me cambié a Ingeniería Civil, en un principio mis papás no me dejaban porque había muy pocas mujeres. Posteriormente logré pasarme en agosto, entré a segundo, prácticamente a final de año. Estoy muy contenta, todos nuestros compañeros nos estiman bastante y lo principal es que nos respetan mucho. Como la mayoría de las materias se basan en la física y matemáticas, se tenía la creencia de que la mujer no servía para este tipo de carreras técnicas, pero se ha comprobado que es tan capaz como el hombre (El Sol de Puebla, 1971, 1 de marzo).

La respuesta segura "es tan capaz como el hombre" muestra ese empoderamiento. No solo conoce su capacidad, sino termina la carrera como ella lo está percibiendo el día de la entrevista. Lo antes escrito da cuenta del abanico de temas e ideas que nos llevan a la reconstrucción de la identidad de género en esa generación, por ahora dejemos ese tema y exploremos otros relacionados con la identidad.

Por su parte, las jóvenes universitarias inquietas leían artículos y libros feministas, tenían interés por conocer lecturas sobre cuál es la condición de las mujeres en otros países, especialmente los socialistas, como China y Cuba. También, las universitarias leían obras de Simone de Bouviere y de marxismo. Surgen pequeñas organizaciones, con inquietudes que se adelantaban a las actividades que se realizarían en 1975, el Año Internacional de la Mujer, cuya sede fue México. En 1973, por vez primera se celebró el 10 de mayo (día de la madre) con una manifestación que partió del edificio Carolino ${ }^{18}$ y terminó con un gran mitin en la Plaza de la Democracia. Las oradoras tomaron la palabra, y desde el balcón de rectoría hablaron de la lucha democrática, y exigieron el esclarecimiento de los asesinatos ocurridos en 1972 y 1973 (Tirado, 2008, 151).

No hay confusión alguna al mencionar lo anterior, reafirmamos, que este grupo de mujeres no eran feministas, aún así no debemos perder las huellas de su lucha solidaria, y reconocer su valiosa presencia en momentos tan difíciles, algunas de ellas llevaban alimentos a quienes como perseguidos políticos debían permanecer en las instalaciones del edificio Carolino. Tampoco podemos olvidar el papel de algunas madres de familia, en ese entonces de la Unión Nacional de Mujeres. Muchos años después, una de aquellas jóvenes reunidas en el grupo de "a. Las meminas", como coloquialmente les decían a las integrantes del "Movimiento por la Emancipación de las Mujeres"19, María

18 Edificio central, donde se encontraba la rectoría y la mayoría de escuelas de la Universidad Autónoma de Puebla. mujeres, se formó con el liderazgo de estudiantes de la Escuela de Economía y de la Preparatoria 
Rosa Márquez Cabrera, con otras mujeres de distintos partidos conformó el "Grupo de Mujeres Plurales", siendo ella diputada por el Partido de la Revolución Democrática (PRD) ${ }^{20}$.

En esta década de 1970, en la ciudad de México, la mayoría de grupos se nucleaban en torno a la reflexión y el análisis de la condición femenina: la maternidad, la doble jornada de trabajo, la sexualidad, etcétera, a través de los "pequeños grupos" de reflexión en el interior de las organizaciones, a fin de plantear trabajos políticos concretos ${ }^{21}$. Mientras tanto en la BUAP se vivían cotidianamente situaciones difíciles para consolidar el proyecto de universidad democrática, crítica y popular, pero fue después de 1978 cuando se asentó este proyecto y surge cierta paz en la universidad por los avances feministas.

Así como el feminismo causó preocupación en gente conservadora, el de la diversidad sexual profundizó los ataques. Para mediados de los setenta la articulación con otras voces feministas pudo darse a través del Partido Revolucionario de los Trabajadores (PRT). En el año de 1975, durante la Conferencia del Año Internacional de la Mujer realizada en la ciudad de México, cuando la palabra LESBIANA se imprime por primera vez en un periódico respetable en este país, en la primera plana de Excélsior del 24 de julio de 1975 se informaba que: "Defendían chicas de EU el homosexualismo" (Hinojosa, 2002, 174-175).

Para entonces, en la ciudad de México ya estaban organizados los grupos de lesbianas y de homosexuales, además se había fundado el Frente de Liberación Homosexual (FLH), del cual solo Nancy Cárdenas, una de las pocas mujeres que participaba, hablaba abiertamente, ya que en 1973 aceptó hablar del tema con el periodista Jacobo Zabludowsky. Dos años más tarde, Nancy Cárdenas, Carlos Monsiváis y Luis González de Alba publicaron y promovieron el primer manifiesto en defensa de los homosexuales del país. Pero si esta manifestación causó estupor en aquella asamblea del 24 de julio de 1975, en Puebla hubiera causado rechazo. El tema de la diversidad sexual quedaba alejado de los objetivos de los grupos que predominaban en 1975. En la ciudad de México, la coordinadora de Grupos Homosexuales toma la decisión de participar en la gran marcha del 2 de octubre de 1978 y a esta asisten varios universitarios de Puebla.

Fue en marzo de 1978, durante las jornadas conmemorativas del Día Internacional de la Mujer, promovidas por el Sindicato de Trabajadores de la

Popular Emiliano Zapata. Una característica de este grupo es que no eran universitarias, lo formaban algunas amas de casa y profesoras; mantenían como punto de identidad entre ellas el que todas eran madres de familia de estudiantes universitarios, sólo algunas esposas de líderes universitarios.

20 Actualmente es Secretaria de Desarrollo Rural y equidad para las comunidades, en el gobierno del Distrito Federal.

21 Es en la década de los ochenta cuando surgen diferentes instituciones académicas que contribuyen a esta discusión: el Programa Universitario de Estudios de Género (PUEG) de la UNAM; en la propia BUAP; en 1982 inició actividades en el Departamento de Política y Cultura de la Universidad Autónoma Metropolitana, plantel Xochimilco, el área Mujer, Identidad y poder (Lau, 2000, 19). 
Universidad Nacional Autónoma de México (STUNAM), cuando surgió la idea de formar un Frente y sería al clausurarse la Conferencia Nacional los días 10 y 11 de marzo de 1979, que se constituyó el Frente Nacional de Lucha por la Liberación y los Derechos de las Mujeres (FNALIDM) y el 15 de marzo el Frente organiza el primer mitin:

frente a la embajada de Irán en protesta por la represión sexista contra las mujeres iraníes. El 31 de marzo en la Cámara de Diputados el Frente se solidarizó con los eventos de ese día llevados a cabo de manera internacional y se manifestaron por el derecho a la maternidad libre y el aborto libre y gratuito. El 19 de abril se realizó en Puebla la primera conferencia por la formación del Frente en este estado (Fuentes, 2012, 158-159)22.

No resulta extraño que sobre lo ocurrido en esta conferencia los periódicos locales guardaran silencio, pues el 29 de abril, en la ciudad de México, cientos de personas realizaron una manifestación a la Basílica de Guadalupe para protestar contra el aborto y el discriminado control de la natalidad (El Sol de Puebla, 1979, 29 de abril).

A finales de los setenta se organizaban talleres, conferencias, discusiones, circunstancia que les permitió trabajar a varias universitarias con Marta Lamas, Amalia García y Esperanza Brito, entre otras mujeres feministas. A casi diez años de haberse iniciado el movimiento feminista en México, en el año de 1978, algunas militantes eran ya reconocidas por su trabajo dentro del mismo.

En Puebla, a finales de 1980 se materializan algunas iniciativas de las feministas en la universidad, no solo con la llegada de Marcela Lagarde en 1976, feminista reconocida e integrante del Partido Comunista de México (PCM) ${ }^{23}$, sino de otras mujeres que desde el sindicalismo impulsaron acciones a favor de las mujeres, incluidos los derechos que ya se tenían en la Ley Federal del Trabajo, apoyaron la creación del Círculo Infantil. Sería Kollontai Poblete quien presentó el proyecto de creación y se hizo cargo del mismo, el cual surgió en el rectorado del ingeniero Luis Rivera Terrazas. El proyecto fue aprobado por las

22 Adriana Fuentes estudió con profundidad y detalle el movimiento lésbico en Puebla, con este tema su tesis de doctorado en historia es pionera en la investigación, pues hasta ahora se ha escrito más sobre el movimiento gay. Sus exhaustivas indagaciones enriquecen el papel que jugaron integrantes del PRT y desmitifica opiniones conservadoras de una parte de la izquierda; asimismo profundiza en los diversos tratamientos psicológicos que en esos años se daban a mujeres lesbianas, tratadas como enfermas psicológicas y anormales por la ciencia. Para documentar su investigación entrevistó a las principales líderes del movimiento y revisó una gran cantidad de documentación en diferentes archivos sobre el período (Fuentes, 2012, 158-159).

23 Marcela Lagarde llega a la BUAP en 1976, funda el Seminario de Antropología de la Mujer, y desde este pequeño grupo de estudiantes difunde las ideas feministas, y es Marcela quien influye en el debate planteado en el seno del PCM, tal como lo reconoce Amalia García. A través de este Seminario Marcela difunde estas ideas, nuclea a jóvenes estudiantes de las que algunas de ellas continúan con el desarrollo de sus investigaciones desde la perspectiva de género. Es en la década de los ochenta cuando surgen diferentes instituciones académicas, y contribuyen en esta discusión, como el Programa Universitario de Estudios de Género, PUEG, de la UNAM; en la propia UAP y en 1982 inició actividades en el Departamento de Política y Cultura de la Universidad Autónoma Metropolitana, plantel Xochimilco, el área Mujer, Identidad y poder. 
autoridades y por el sindicato, se basaba en el modelo "aprender haciendo". El inicio fue con la ayuda de tres educadoras, cuatro auxiliares de educadoras, una auxiliar de enfermería, una trabajadora social, dos auxiliares de cocina, una cocinera y un portero, personal que era suficiente para atender a 25 niños. Después, fue una prestación sin duda beneficiosa para muchas trabajadoras, pues entonces no había guarderías, ni estancias infantiles. La mayoría de las universitarias, madres de familia, resolvían esta necesidad como tradicionalmente se hacía, con la ayuda familiar.

El movimiento feminista se ocuparía de temas ejes como la violencia contra la mujer, el derecho al aborto y reivindicaciones que aunque estipuladas en la Ley Federal del Trabajo, debían incluirse en el Contrato colectivo de trabajo, como el permiso con goce de salario por tres meses por maternidad.

\section{Conclusiones}

Es notoria la incorporación de las universitarias a la planta docente, cambio significativo en relación con los años anteriores, como también su inclusión a los órganos de representación estudiantil e institucional, por ejemplo en el Consejo Universitario y en comités de lucha. Asimismo, sus huellas se vuelven visibles con el acceso a carreras, incluso a aquellas altamente masculinizadas, como Ingeniería Civil, hasta entonces considerada "la isla de los hombres solos".

En las opiniones que vierten las universitarias, en las entrevistas publicadas en los periódicos locales, se percibe un mayor interés por desenvolverse en el espacio público, al terminar la carrera, es decir han desarrollado otra ideación de sí mismas.

El otro eje interesante en este proceso es la sexualidad, que se refleja en las prácticas sexuales, la unión libre, el uso de su libertad para decidir ser madres, así como la posposición de esta. Decisiones individuales que cruzan con decisiones colectivas y compromisos ideológico-políticos. La defensa de la universidad es el punto medular de su actuar y en esta se comprometen con las diferentes izquierdas, al finalizar la década de los setenta observan un interés por las ideas feministas y por la condición de las mujeres en otros países, especialmente del bloque socialista, sin dejar de observar al movimiento feminista francés o el norteamericano. En la década de los ochenta el movimiento feminista ha cobrado presencia en la universidad.

No sobra considerar que durante la década de los setenta surgen los sindicatos universitarios en el país. En 1975 en la UAP surgirían también, la primera huelga estalló en 1976. La incorporación de muchas universitarias a la lucha por sus derechos y al apoyo y solidaridad con trabajadores de otras instituciones fomentó nuevas redes sociales, en las que se impulsó intercambio de ideas y entre ellas el feminismo permeó la reivindicación de sus derechos como trabajadoras. 


\section{Referencias}

Allier, Eugenia. (2012). El movimiento estudiantil de 1968 en México: historia, memoria y recepciones. En el Castillo Troncoso, Alberto. (Ed.). Reflexión y crítica en torno al movimiento estudiantil de 1968. Nuevos enfoques y líneas de investigación. México: Instituto de Investigaciones Dr. José María Luis Mora.

Aróstegui, Julio. (2004). Generaciones y cambio histórico. En Aróstegui, Julio. La historia vivida. Sobre la historia del presente. Madrid: Alianza Editorial.

Contradicción mundial sobre la píldora. (1970, 19 de enero). El Sol de Puebla, 1-3.

Dávila Peralta, Nicolás. (2001). Las santas batallas. El anticomunismo en Puebla. Puebla: Gobierno del Estado de Puebla-Benemérita Universidad Autónoma de Puebla-Cuadernos del Archivo Universitario.

Díaz Escoto, Alma Silvia. (2008). Las mujeres en los movimientos estudiantiles de 1968 y de 1999-2000. Hacia la emancipación y el empoderamiento. En Tirado Villegas, Gloria. (Ed.). De la filantropía a la rebelión. Mujeres en los movimientos sociales, finales del siglo XIX al siglo XXI. Puebla: Benemérita Universidad Autónoma de Puebla-Vicerrectoría de Investigación y Estudios de Posgrado-Cuerpo Académico de Estudios Históricos.

Ergas, Yasmine. (1994). El sujeto mujer: el feminismo de los años setentaochenta. En Duby, George y Perrot, Michelle. (Eds.). Historia de las mujeres. Madrid: Taurus.

Frazier, Lessie Jo y Cohen, Deborah. (2001). Género, terreno y acción en el 68: la participación femenina y la ciudadanía social en México. En CD El 68, Nuevos enfoques. Memoria Seminario Nacional de Movimientos Estudiantiles Mexicanos en el siglo XIX. México: Universidad Nacional Autónoma de México-Instituto de Investigaciones Bibliográficas.

Frazier, Lessie Jo y Cohen, Deborah. (November 2003). Mexico ‘68: Defining the Space of the Movement, Heroic Masculinity in the Prison, and Women' in the Streets. En Hispanic American Historical Review, Vol. 83, 4.

Fuentes, Adriana. (2012). Cronopías segando rigidez, blandiendo libertad. Una historia de visibilidad a través de algunas protagonistas del movimiento lésbico en México, 1977-1997. Tesis de Doctorado en Historia y Etnohistoria, Escuela Nacional de Antropología e Historia-Instituto Nacional de Antropología e Historia-Secretaría de Educación Pública.

González Ruiz, Edgar. (2004). Muro, memorias y testimonios, 1961-2002. Puebla: Gobierno del Estado de Puebla, Benemérita Universidad Autónoma de Puebla, Cuadernos del Archivo Histórico Universitario. 
González, Argelia Beatriz. (2010). Mujeres somos y en el 68 anduvimos. activismo en la calle. En CD Coloquio Internacional: Las mujeres mexicanas y sus revoluciones a lo largo de dos siglos. México: Universidad de Guanajuato, División de Ciencias Sociales y Humanidades, Departamento de Historia, s.p.

González, Argelia Beatriz. (2011). Las mujeres del 68: de la fotografía a la historia. El caso del periódico La Prensa. Tesis de Licenciatura en Historia. México: Escuela Nacional de Antropología e Historia-Instituto Nacional de Antropología e Historia-Secretaría de Educación Pública.

Hinojosa, Claudia. (2002). Gritos y susurros. Una historia sobre la presencia pública de las feministas lesbianas. En Gutiérrez Castañeda, Griselda. (Ed.). Feminismo en México revisión histórico-crítica del siglo que termina. México: Programa Universitario de Estudios de Género-Universidad Nacional Autónoma de México.

Holland, Jack. (2007). Una breve historia de la misoginia. El prejuicio más antiguo del mundo. México: Editorial Océano.

Lau, Ana. (2000). El nuevo movimiento feminista mexicano a fines del milenio. En Bartra, Elí y Lau, Ana. (Eds.). Feminismo en México, ayer y hoy. México: Instituto Mora-Universidad Autónoma Metropolitana-Xochimilco, Col. Molinos de Viento.

Manifestación a la Basílica de Guadalupe. (1979, abril 29). El Sol de Puebla, p. 2.

Quijano, Mercedes. (s.f.). La situación de la mujer en la UAP. Crítica, Revista de la Universidad Autónoma de Puebla, No. 17.

Rivera, Elva. (2010). De la manifestación al aula. Saberes, silencios e inequidades en la Universidad Autónoma de Puebla (1972-2001). Tesis de Doctorado en Historia. México: Universidad Veracruzana-Instituto de Investigaciones Histórico-Sociales.

Sabatié, Caroline. (2006). Le mouvement 'etudiant au Mexique: l'emancipation féminine en marche. Recuperado el 13 de diciembre de 2013, de: http:// halshs.archives-ouvertes.fr/halshs-00490021

Sánchez Sáenz, Ana María. (2008). Los libros del movimiento estudiantil de 1968. Gaceta UNAM, Órgano informativo de la UNAM, Número Especial Memoria del Movimiento estudiantil.

Sotelo, Humberto. (2002). 1972-1973, Puebla de los demonios. Puebla: Gobierno del Estado de Puebla-Benemérita Universidad Autónoma de Puebla. Cuadernos del Archivo Histórico de Puebla. 
Tirado Villegas, Gloria A. (2004). La otra historia. Voces de mujeres del 68, Puebla. Puebla: Benemérita Universidad Autónoma de Puebla-Instituto Poblano de la Mujer.

Tirado Villegas, Gloria A. (2008). Las mujeres en torno al movimiento estudiantil de los setenta. En Tirado Villegas, Gloria A. (Ed.). De la filantropía a la rebelión. Mujeres en los movimientos sociales, finales del siglo XIX al siglo XXI. Puebla: Cuerpo Académico de Estudios Históricos-Benemérita Universidad Autónoma de Puebla-Vicerrectoría de Investigación y Estudios de Posgrado, 137-157.

Tirado, Gloria A. (2009). Abriendo brecha: Mujeres universitarias poblanas del siglo XX. México, Puebla, Fomento Editorial Benemérita Universidad Autónoma de Puebla.

Tirado, Gloria A. (2010). De la historia a la nostalgia Memoria colectiva, el 68 en Puebla, México. Revista Diálogos, No. 1-2, Vol. 5.

Tirado, Gloria A. (2012). De añoranzas, testimonios y de empoderamiento. En del Castillo Troncoso, Alberto. (Ed.). Reflexión y crítica en torno al movimiento estudiantil de 1968. Nuevos enfoques y líneas de investigación. México: Instituto de Investigaciones Dr. José María Luis Mora, Serie Historia Social y Cultural.

Unidos en la defensa de la familia. (1978, abril 21). El Sol de Puebla, Puebla, p. 2.

Vázquez, Verónica. (2009). Sexualidad, género y dominación simbólica. La doble moral y el sexo por amor. Graffylia, Vol. 8-9. 